\title{
Experimental study of multiple pilot injection strategy in an automotive direct injection diesel engine
}

\author{
Plamen Punov ${ }^{1, *}$, Tsvetomir Gechev ${ }^{1}$, Svetoslav Mihalkov ${ }^{1}$, Pierre Podevin ${ }^{2}$, and Dalibor Barta ${ }^{3}$ \\ ${ }^{1}$ Technical University - Sofia, Department of combustion engines, automobiles and transport, 1000 Sofia, Bulgaria \\ ${ }^{2}$ Laboratoire de Chimie Moléculaire, Génie des procédés Chimiques et Energétique, EA7341, \\ Conservatoire National des Arts et Métiers, HESAM Université, 75003 Paris, France \\ ${ }^{3}$ University of Zilina, Faculty of Mechanical Engineering, Univerzitna 8215/1, 010 26, Žilina, Slovakia
}

\begin{abstract}
The pilot injection strategy is a widely used approach for reducing the noise of the combustion process in direct injection diesel engines. In the last generation of automotive diesel engines up to several pilot injections could occur to better control the rate of heat release (ROHR) in the cylinder as well as the pollutant formation. However, determination of the timing and duration for each pilot injection needs to be precisely optimised. In this paper an experimental study of the pilot injection strategy was conducted on a direct injection diesel engine. Single and double pilot injection strategy was studied. The engine rated power is $100 \mathrm{~kW}$ at $4000 \mathrm{rpm}$ while the rated torque is $320 \mathrm{Nm}$ at $2000 \mathrm{rpm}$. An engine operating point determined by the rotation speed of $1400 \mathrm{rpm}$ and torque of $100 \mathrm{Nm}$ was chosen. The pilot and pre-injection timing was widely varied in order to study the influence on the combustion process as well as on the fuel consumption.
\end{abstract}

\section{Introduction}

Recently, a more demanding emissions homologation procedure for light duty vehicle was imposed by the EU. It includes a new test cycle called WLTC as well as a real drive emission test [1]. In order to validate the results a conformity factor was proposed which would be decreased in the following years. Moreover, in 2020 the reference $\mathrm{CO}_{2}$ emissions will be decreased to $95 \mathrm{~g} / \mathrm{km}$ which represents a reduction by $27 \%$ in comparison with 2015. Although many companies have already announced that diesel engines will not be used in their new passenger cars any more, the main advantage of diesel engines, i.e. higher thermal efficiency, can still be important in order to reduce $\mathrm{CO}_{2}$ emissions.

A number of studies are now focused on posttreatment in diesel engines. However, the emissions, noise and fuel consumption could be improved by split injection strategy usually provided by the last generation commonrail fuel injection systems [2, 3]. The split injection strategy can also be used for control of nonconventional combustion processes such as HCCI, RCCI, LTC, etc. [4].

Pilot injections are mainly used to reduce the ignition delay period, which leads to low combustion noise. Finesso and Spessa in [5] studied ignition delay in the case of multiple injection for a light-duty DI diesel engine. On the basis of an experimental and numerical approach they proposed controlled-orientated correlations for prediction of the ignition delays for both the pilot and the main injection. According to [6], the ROHR in the case of a pilot injection could be interpolated by double Vibe function. A numerical study of the influence of pre- injection strategy on ignition and combustion was presented by Punov and Evtimov in [7]. In the case of single pre-injection, the maximum ROHR can be reduced by $25 \%$ at $2000 \mathrm{rpm}$ and BMEP of 8 bars. In [8] the pilotmain injection strategy was studied by means of endoscopic visualisation. The results revealed that small pilot injection and late start of the pilot injection reduced the ignition delay period, so that the rate of heat release peak decreased. Additionally, it leads to lower soot emission due to better oxidation of the soot.

Moreover, pilot injections affect the formation of $\mathrm{NO}_{\mathrm{x}}$ and PM due to the influence on the premixed and mixed combustion phase. Park et al. [9] studied the combustion and emission characteristics of a single cylinder diesel engine. Three different strategies of split injection were proposed. The results revealed that the increase of the injection interval between the first and second injection caused an increase of $\mathrm{NO}_{\mathrm{x}}$ and $\mathrm{HC}$ while $\mathrm{PM}$ and $\mathrm{CO}$ were reduced. Late SOI leads to lower $\mathrm{NO}_{x}, \mathrm{CO}$ and $\mathrm{HC}$. At the same time the PM was increased. Xu et al. [10] reported a significant impact of the start of the pilot injection when a diesel engine is fuelled with natural gas. Pre-injection timing higher than $70^{\circ} \mathrm{BTDC}$ leads to lower maximum pressure and lowered $\mathrm{NO}_{\mathrm{x}}$ emission by $35 \%$. The split injection strategy was studied by How et al. in [11] for a diesel engine using biodiesel blends. The experimental test was conducted on a light-duty diesel engine as single, double and triple injections were applied for different fuel blends. It was found out that considerably lower level of $\mathrm{NO}_{\mathrm{x}}$ emission could be achieved by retarding the $\mathrm{SOI}$ in case of triple injection for B20 and B50 fuel blends. Li et al. studied the effect of multiple-injection strategies on the

\footnotetext{
* Corresponding author: plamen_punov@tu-sofia.bg
} 
particle size and structure in [12]. The pilot-injection strategy in comparison with the single injection leads to increased number and mass of the particles with diameter above $0.1 \mu \mathrm{m}$. However, due to later oxidation in combustion, the particle number and diameter are reduced.

The swirl in combination with split injection could provide a positive effect on the combustion [13]. The higher the swirl ratio, the shorter the combustion duration. The combustion duration can be reduced by $19.5-25.7 \%$ depending on the pilot quantity. At the same time the BSFC and Soot emission are reduced.

The optimization of the multiple injection strategy is not easy to be done due to the impact of many injection parameters as well as the control system limitation. Millo et al. [14] used a genetic algorithm in order to optimize control parameters such as SOI, rail pressure, injection quantity, boost pressure, etc. in the case of a split injection strategy by 5 separate injections.

On the basis of the literature survey a lot of split injection strategies were studied in DI diesel engines. However, not a lot of research was reported on the influence of dual pilot injection on the combustion characteristics. In view of that, the aim of this paper is to study the impact of single and double pilot injection strategies applied to a passenger car DI diesel engine.

\section{Experimental equipment}

\subsection{Engine under study}

It is a DI diesel engine with displacement of 21 , which complies with EURO IV emission standard. The engine is equipped with a Common-Rail injection system, VG turbocharger, water cooled exhaust gas recirculation (EGR), catalytic converter, etc. The maximum engine power is $100 \mathrm{~kW}$ at $4000 \mathrm{~min}^{-1}$ and the maximum torque is $320 \mathrm{Nm}$ at $2000 \mathrm{~min}^{-1}$. The boost pressure is limited to
1.3 bar. The main parameters of the engine are listed in Table 1.

Table 1. Engine specifications.

\begin{tabular}{|l|l|}
\hline Engine type & HDI \\
\hline Number of cylinders & 4 \\
\hline Displacement & 21 \\
\hline Bore & $85 \mathrm{~mm}$ \\
\hline Stroke & $88 \mathrm{~mm}$ \\
\hline Compression ratio & 17.6 \\
\hline Maximum Rail Pressure & 1600 bar \\
\hline
\end{tabular}

\subsection{Engine test bed}

The engine was mounted on an engine test bed as it is shown in Fig. 1. An eddy-current dynamometer was used with a maximum power of $160 \mathrm{~kW}$ and maximum speed of $10000 \mathrm{rpm}$. The brake is electronically controlled by means of Schenck control unit. In order to study the incylinder combustion the first cylinder is equipped with piezoelectric pressure sensor. The sensor replaces the glow plug of the cylinder. Signal from the sensor is transmitted to a Kistler Type 5011 charge amplifier, then to the AVL measurement unit. The crankshaft angular position is registered by means of optical encoder. The fuel consumption is measured by means of a volumetric flow meter Rotronics RCC101.

Table 2. Test equipment specification.

\begin{tabular}{|l|l|}
\hline Eddy-current brake & $160 \mathrm{~kW} / 10000 \mathrm{rpm}$ \\
\hline Brake control & Schenck \\
\hline Pressure sensor AVL GH13P & 250 bars \\
\hline Signal amplifier Kistler & Type 5011 \\
\hline Angle encoder AVL 364C & 0.1 CAD \\
\hline Optical signal converter & AVL 364 \\
\hline Measurement system & AVL Indiscop 647 \\
\hline Fuel flow measurement & Rotronics RCC 101 \\
\hline
\end{tabular}

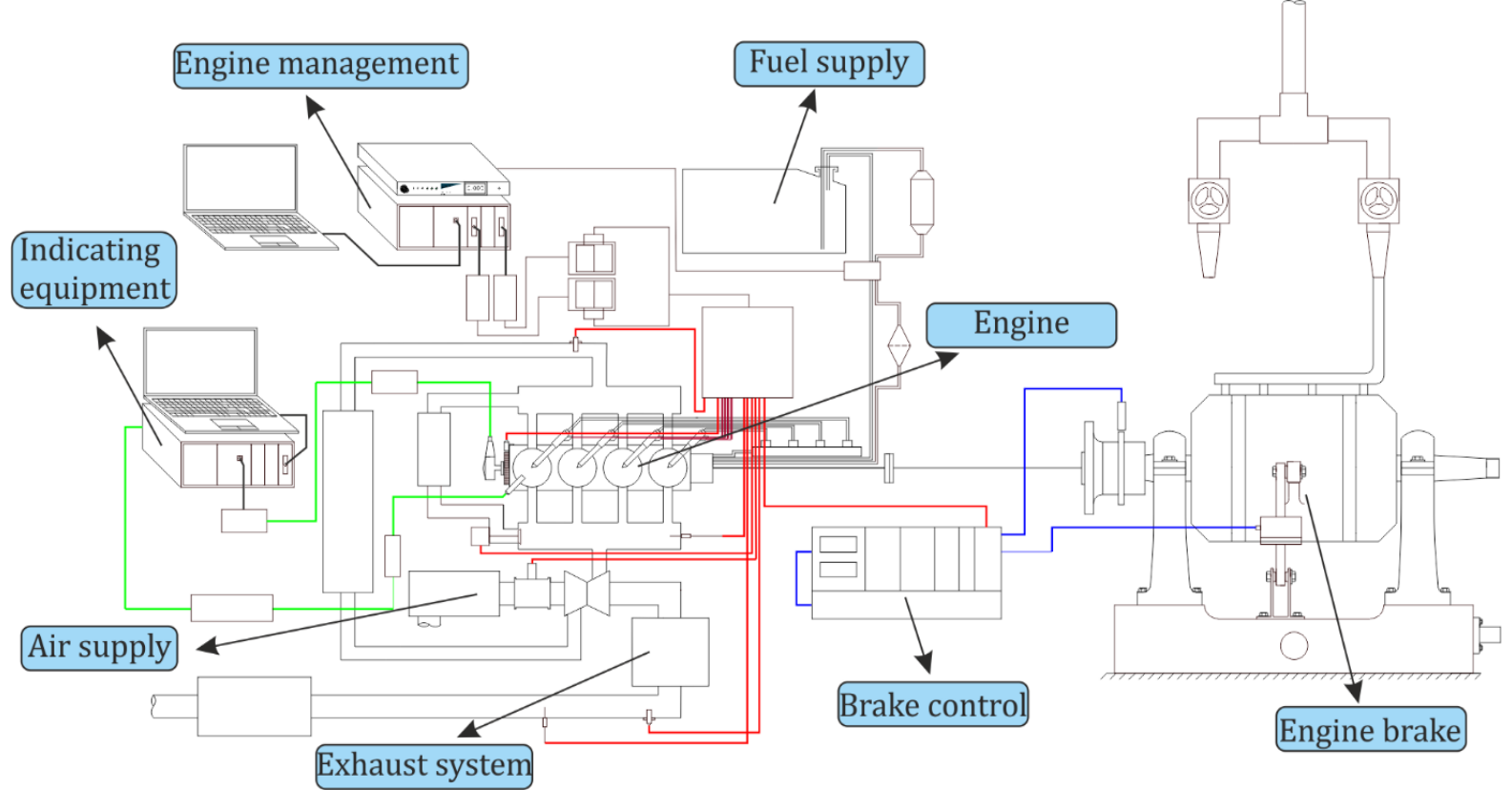

Fig. 1. Schematic diagram of the engine test bed. 


\subsection{Engine management and data logging}

The engine management system is based on a National Instruments real-time controller. The hardware of the system consists of PXI chassis - NI PXI-1031, Real-Time Embedded Controller - NI PXI-8106 RT, FPGA module - NI PXI-7813R, two R Series Expansion Chassis - NI CRIO 9151 as well as the modules developed by Drivven. In our project we used four modules: DI Driver -2 pcs., Low Side, $\mathrm{AD}$ Combo and $\mathrm{O}_{2}$ sensor module. All of these modules are based on NI C series interface.

The entire system provides a large functionality for real-time control and monitoring of the engine control parameters such as: injection control by up to five injections per cycle, injection pressure control, boost pressure control, exhaust gas recirculation (EGR) control, closed-loop control of injection by means of wide band oxygen sensor in exhaust gases, etc.

A LabVIEW project was developed in order to determine the control logic of the management system. The real-time data were visualized by means of the software called CalView developed by Drivven. This software was also used to set the operating parameters in real-time.

\section{Experimental results}

The experimental test was conducted at $1400 \mathrm{rpm}$ and engine torque of $100 \mathrm{Nm}$. This operating point is a representative point in both the WLTC and RDE tests for passenger cars. The EGR rate is zero. Two pilot injection strategies were studied: a single pilot injection and a double pilot injection. In order to study the influence on the combustion characteristics as well as on the fuel consumption, the engine output torque was constant. The torque was controlled through the duration of the main injection.

\subsection{Single pilot-injection}

Firstly, a single pilot injection strategy was studied. In this case the pilot injection was provided with a constant duration (constant energizing time). In order to study the influence of the pilot injection, the start of the pilot injection was varied within the range of $0.8 \mathrm{~ms}$ to $2 \mathrm{~ms}$ before the start of main injection. The start of the main injection was constant $2^{\circ}$ BTDC. The torque of the engine was controlled by variation of the main injection duration. It was conducted automatically by means of the engine management system. The variation of the main engine control parameters is listed in Table 3.

Table 3. Injection parameters of single pilot injection.

\begin{tabular}{|l|l|}
\hline Engine speed & $1400 \mathrm{rpm}$ \\
\hline Engine output torque & $100 \mathrm{Nm}$ \\
\hline Rail pressure & $620 \mathrm{bars}$ \\
\hline Start of main injection & $2^{\circ}$ BTDC \\
\hline Duration of main injection & variable \\
\hline Start of pilot injection & $0.8 \ldots 2 \mathrm{~ms}$ \\
\hline Duration of pilot injection & $0.35 \mathrm{~ms}$ \\
\hline
\end{tabular}

The start of the pilot injection was varied by a step of $0.2 \mathrm{~ms}$. Estimated in CAD the variation is in the range of $7^{\circ} \mathrm{BTDC}$ to $18.8^{\circ} \mathrm{BTDC}$. The results concerning the indicated diagram are presented in Fig. 2.

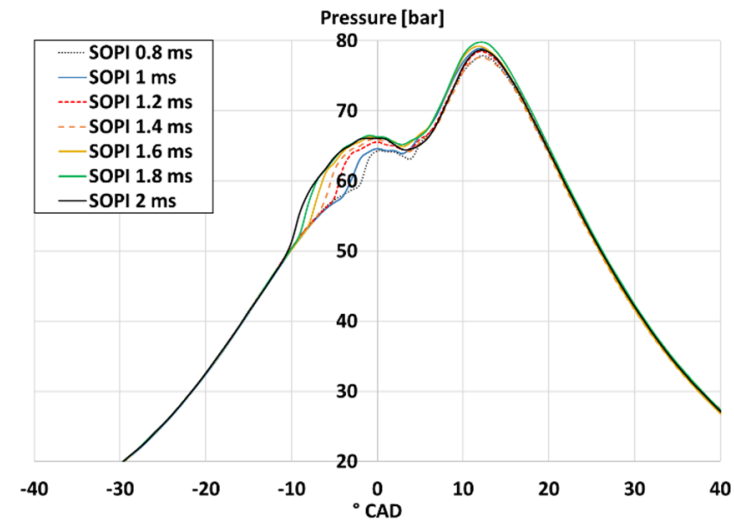

Fig. 2. In-cylinder pressure as a function of start of pilot injection.

The start of the pilot injection has a significant impact on the in-cylinder pressure. The early injection leads to an early start of combustion and to higher pressure before TDC. No big impact on the ignition delay period of pilot injection or on the ignition delay of the main injection was not found. The maximum of the pressure peak was observed to be at the same CAD for all studied cases. The highest in-cylinder pressure was observed in the case when the pilot injection started $1.8 \mathrm{~ms}$ before the start of the main injection - it amounted to 79.8 bar. The lowest in-cylinder pressure peak was observed when the pilot injection start was $0.8 \mathrm{~ms}$ before the start of the main injection. In this case the maximum in-cylinder pressure was observed to be 77.8 bars. The fuel consumption varied by $1.44 \%$ and the lowest consumption was observed at the latter pilot injection.

\subsection{Double pilot-injection}

The second study was conducted as one more injection, so called pre-injection, was added between the pilotinjection and the main injection. The start of the pilot injection (2 ms BTDC), as well as its duration, were nonvariable during this study. The start of the main injection was also set to $2^{\circ}$ BTDC while its duration was used to control the engine torque. In this case the impact of the start of the pre-injection was studied. The pre-injection duration was fixed to $0.25 \mathrm{~ms}$ (energizing time). The start of the injection was varied within the range of $0.5 \mathrm{~ms}$ to $1.3 \mathrm{~ms}$ before the start of main injection. These are shown in Fig. 3.

The pre-injection leads to higher pressure before the start of combustion of the main injected fuel while the maximal pressure in the cylinder has very similar value to the one in the first study. The highest pressure peak was observed when the pre-injection starts $1 \mathrm{~ms}$ before the main injection while the lowest pressure peak was observed at the pre-injection starting $1.3 \mathrm{~ms}$ before the main injection. In this study a small impact on the engine fuel consumption was observed within the range of $0.75 \%$. 


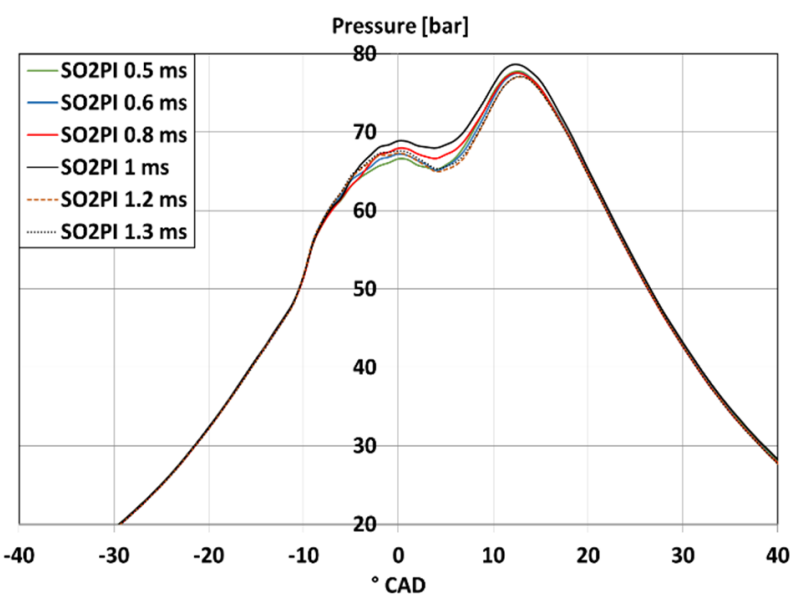

Fig. 3. In-cylinder pressure as a function of start of preinjection.

\section{Analysis of the combustion characteristics and discussion}

In order to better understand the impact of the multiple pilot injection strategy on the combustion process, the ROHR was compared for each studied case. The ROHR is related to the combustion noise as well as to the pollutant formation. The ROHR was estimated by means of simulating programme in the range of $30^{\circ}$ BTDC to $90^{\circ}$ ATDC. The results are shown in Figures 4 and 5 as well as in Table 4.

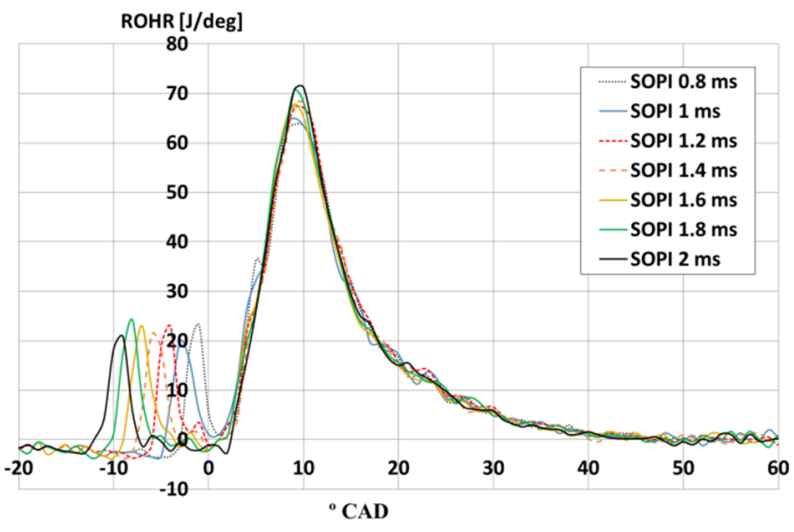

Fig. 4. ROHR for single pilot injection study.

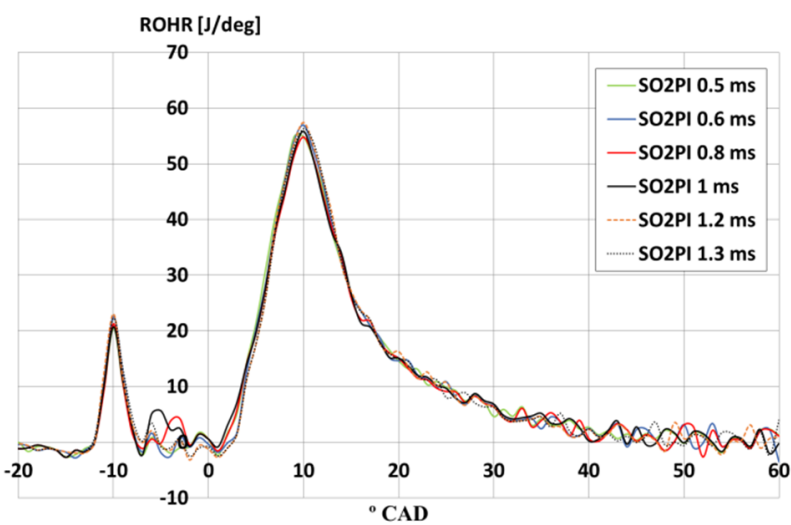

Fig. 5. ROHR for double pilot-injection study.
The start of the pilot injection in the case of single pilot-injection strategy has a slight impact on the peak of ROHR. Early pilot injection leads to a higher peak while the closer the start of the pilot injection to the main injection, the lower the ROHR peak. In the first case, the maximum ROHR was estimated to be $71.2 \mathrm{~J} / \mathrm{deg}$ while the maximum decreases to $63.5 \mathrm{~J} / \mathrm{deg}$ in retarded pilot injection.

Obviously, double pilot-injection strategy has a positive impact on the ROHR peak. Although, the preinjection in our study was quite small as quantity, the peak was reduced to $54 \mathrm{~J} / \mathrm{deg}$. The start of the pre-injection does not lead to significant variation in the ROHR curve. However, we could expect lower noise levels as well as less $\mathrm{NO}_{\mathrm{x}}$ emissions.

Table 4. Maximum in-cylinder pressure and ROHR.

\begin{tabular}{|c|c|c|c|}
\hline \multicolumn{4}{|c|}{ Single pilot-injection strategy } \\
\hline $\begin{array}{c}\text { Start of pilot } \\
\text { injection, } \\
{ }^{\circ} \text { BTDC }\end{array}$ & $\begin{array}{c}\text { Start of pre- } \\
\text { injection, } \\
{ }^{\circ} \text { BTDC }\end{array}$ & $\begin{array}{c}\text { Maximum } \\
\text { pressure, } \\
\text { bar }\end{array}$ & $\begin{array}{c}\text { Maximum } \\
\text { ROHR, } \\
\text { J/deg }\end{array}$ \\
\hline 8.7 & - & 77.8 & 63.5 \\
\hline 10.4 & - & 78.9 & 65 \\
\hline 12.0 & - & 78.5 & 67.1 \\
\hline 13.8 & - & 77.6 & 67.9 \\
\hline 15.4 & - & 79.2 & 67.8 \\
\hline 17.1 & - & 79.8 & 70.5 \\
\hline 18.8 & - & 78.7 & 71.2 \\
\hline \multicolumn{5}{|c|}{ Double pilot-injection strategy } \\
\hline $\begin{array}{c}\text { Start of pilot } \\
\text { injection, } \\
{ }^{\circ} \text { BTDC }\end{array}$ & $\begin{array}{c}\text { Start of pre- } \\
\text { injection, } \\
{ }^{\circ} \text { BTDC }\end{array}$ & $\begin{array}{c}\text { Maximum } \\
\text { pressure, } \\
\text { bar }\end{array}$ & $\begin{array}{c}\text { Maximum } \\
\text { ROHR, } \\
\text { J/deg }\end{array}$ \\
\hline 18.8 & 6.2 & 77.7 & 54.8 \\
\hline 18.8 & 7.0 & 76.8 & 56.9 \\
\hline 18.8 & 8.7 & 77.4 & 54.8 \\
\hline 18.8 & 10.4 & 78.6 & 55.8 \\
\hline 18.8 & 12.0 & 77 & 57.4 \\
\hline 18.8 & 12.9 & 77.1 & 56.3 \\
\hline \multicolumn{5}{|c|}{}
\end{tabular}

\section{Conclusion}

Multiple pilot-injections strategy was experimentally studied in a modern diesel engine intended for passenger cars. Two strategies were compared: single pilot-injection and double pilot-injection. In both cases, the varied parameter was the start of the pilot or pre-injection. For each of the injections the in-cylinder pressure values were recorded and the ROHR was then estimated.

On the basis of our experimental results, it could be stated that the double pilot injections strategy has a significant potential to reduce the maximum of the ROHR in the combustion chamber by up to $13.7 \%$ in comparison to the single pilot injection. The start of the pilot injection in the case of a single pilot injection strategy and the start of pre-injection in the case of the double pilot injection offer a slight impact on the maximum of the cylinder pressure. Early start of the pilot injection leads to higher negative piston work. Therefore, it increases fuel consumption by $1.44 \%$ in comparison to the latter injection. In double pilot injection strategy, the preinjection timing has lower impact to the to the fuel 
consumption up to $0.75 \%$. However, in case of double pilot-injection the fuel consumption increases due to the second injection before the main injection.

In order to fully optimise the fuel injection in DI diesel engines more injection parameters, such as injection pressure, injection duration and post-injection, need to varied. This will be the subject of another research that will take into consideration pollutant emissions as well.

Special acknowledgements to Mr. Pierre Podevin from laboratory CMGPCE of Cnam, Paris, who provided to the Department of Combustion engines, automobiles and transport of TU-Sofia an eddy-current brake and an electronic control device. Also, the authors would like to thank Mr. Theo Bosaert and Mr. Cyril Fresque who during their internship helped us to install the engine test equipment in our laboratory.

\section{Nomenclature}

$\begin{array}{ll}\mathrm{CO}_{2} & \text { carbon dioxide } \\ \mathrm{CO} & \text { carbon monoxide } \\ \mathrm{NO}_{\mathrm{x}} & \text { nitrogen oxides } \\ \mathrm{HC} & \text { hydrocarbons }\end{array}$

\section{Abbreviations}

\begin{tabular}{|c|c|}
\hline ATDC & after top dead center \\
\hline BMEP & brake mean effective pressure \\
\hline BSFC & brake specific fuel consumption \\
\hline BTDC & before top dead center \\
\hline CAD & crank angle degree \\
\hline DI & direct injection \\
\hline EGR & exhaust gas recirculation \\
\hline $\mathrm{HCCI}$ & homogenous charge compression ignition \\
\hline LTC & low-temperature combustion \\
\hline PM & particulate matter \\
\hline RCCI & reactivity controlled combustion ignition \\
\hline $\mathrm{RDE}$ & real drive emission \\
\hline ROHR & rate of heat release \\
\hline SOI & start of injection \\
\hline VG & variable geometry \\
\hline WLTC & Worldwide harmonized Light vehicles Test \\
\hline
\end{tabular}

\section{References}

1. A. Clenci, Real Driving Emissions (RDE): enjeux et défis, Conférences CNAM-SIA-LMP-ENSPM (2018)

2. P. Punov, Research the fuel injection characteristics of a Common Rail solenoid injector, Proceedings of BulTrans-2015, 153-158 (2015)

3. G. Dober, S. Tullis, G. Greeves, N. Milovanovic, M. Hardy, S. Zuelch, The impact of injection strategies on emissions reduction and power output of future diesel engines, SAE Conference Proceedings, 2008-01-0941 (2008)

4. K. Mathivanan, J. Mallikarjuna, A. Ramesh, Influence of multiple fuel injection strategies on performance and combustion characteristics of a diesel fuelled HCCI engine - An experimental investigation, Experimental Thermal and Fluid Science, 77, 337-346 (2016)
5. R. Finesso, E. Spessa, Ignition delay prediction of multiple injections in diesel engines, Fuel, 119, 170190 (2014)

6. P. Punov, N. Milkov, C. Perilhon, P. Podevin, T. Evtimov, Study on the combustion process in a modern diesel engine controlled by pre-injection strategy, IOP Conference Series: Materials Science and Engineering, 252(1), 23, Article number 012090, (2017)

7. P. Punov, T. Evtimov, Combustion optimization in a modern diesel engine by means of pre-injection strategy, International Journal MTM, 4, 41-44 (2015)

8. X. Li, W. Yang, L. Zhao, F. Liu, The influence of pilot-main injection matching on DI diesel engine combustion using an endoscopic visualization system, Fuel, 188, 575-585 (2017)

9. S. Park, H. Kim, D. Shin, J. Lee, Effects of various split injection strategies on combustion and emissions characteristics in a single-cylinder diesel engine, Applied Thermal Engineering, 140, 422-431 (2018)

10. M. Xu, W. Cheng, Z. Li, H. Zhang, T. An, Z. Meng, Pre-injection strategy for pilot diesel compression ignition natural gas engine, Applied Energy, 179, 1185-1193 (2016)

11. H. How, H. Masjuki, M. Kalam, Y. Teoh, Influence of injection timing and split injection strategies on performance, emissions, and combustion characteristics of diesel engine fueled with biodiesel blended fuels, Fuel, 213, 106-114 (2018)

12. X. Li, C. Guan, Y. Luo, Z. Huang, Effect of multipleinjection strategies on diesel engine exhaust particle size and nanostructure, Journal of Aerosol Science, 89, 69-76 (2015)

13. X. Li, H. Zhou, L. Zhao, L. Su, H. Xu, F. Liu, Effect of split injections coupled with swirl on combustion performance in DI diesel engines, Energy Conversion and Management, 129, 180-188 (2016)

14. F. Millo, P. Arya, F. Mallamo, Optimization of automotive diesel engine calibration using genetic algorithm techniques, Energy, 158, 807-819 (2018) 